\title{
Patient Disconnect
}

To the Editor,

We would like to bring to your attention an event which occurred recently in the operating room. A 35-year-old ASA I man was scheduled for septorhinoplasty. After induction of anaesthesia with fentanyl and propofol, tracheal intubation was facilitated with succinylcholine. Anaesthesia was maintained with $\mathrm{O}_{2} 33 \%$ in $\mathrm{N}_{2} \mathrm{O}$ and isoflurane $0.8-1.5 \%$. Ventilation was manually supported until resumption of spontaneous respiration.

The $\mathrm{P}_{\mathrm{ET}} \mathrm{CO}_{2}(40-50 \mathrm{mmHg}), \mathrm{SpO}_{2}(97-100 \%)$ and respiratory rate $(14-18 \mathrm{bpm})$ remained stable throughout the operation. Forty minutes after the start of surgery, it was noted that the reservoir bag, which remained inflated, ceased to move with respiration. At that stage the $\mathrm{P}_{\mathrm{ET}} \mathrm{CO}_{2}$ was $45 \mathrm{mmHg}, \mathrm{F}_{\mathrm{I}} \mathrm{O}_{2}$ was 0.33 , $\mathrm{SpO}_{2}$ was $99 \%$, respiratory rate was $18 \mathrm{bpm}$ and ET isoflurane was $1.0 \%$. However, the inspired $\mathrm{PCO}_{2}$ increased from a baseline of $3 \mathrm{mmHg}$ to $12 \mathrm{mmHg}$.

It was noted that the patient was disconnected from the breathing circuit at a site distal to the gas sampling line. In effect, the surgical drapes had formed a tent allowing accumulation of fresh gas. This provided an adequate inspired $\mathrm{O}_{2}, \mathrm{~N}_{2} \mathrm{O}$ and isoflurane. However the resultant rebreathing of $\mathrm{CO}_{2}$ and diminished movement of the reservoir bag alerted us to the problem. In this situation, the $\mathrm{P}_{\mathrm{ET}} \mathrm{CO}_{2}$ may not be a reliable indicator of a circuit disconnection in a spontaneously breathing patient.

Linda M. Collins FFARCSI

Himat Vaghadia FRCPC

Vancouver Hospital and Health Sciences Centre

Vancouver, BC Canada 